\title{
Nutrient intake and risk of open-angle glaucoma: the Rotterdam Study
}

\author{
Wishal D. Ramdas $\cdot$ Roger C. W. Wolfs $\cdot$ Jessica C. Kiefte-de Jong \\ Albert Hofman · Paulus T. V. M. de Jong • Johannes R. Vingerling • \\ Nomdo M. Jansonius
}

Received: 30 October 2011/ Accepted: 23 February 2012/Published online: 30 March 2012

(C) The Author(s) 2012. This article is published with open access at Springerlink.com

\begin{abstract}
Open-angle glaucoma (OAG) is the commonest cause of irreversible blindness worldwide. Apart from an increased intraocular pressure (IOP), oxidative stress and an impaired ocular blood flow are supposed to contribute to OAG. The aim of this study was to determine whether the dietary intake of nutrients that either have anti-oxidative properties (carotenoids, vitamins, and flavonoids) or influence the blood flow (omega fatty acids and magnesium) is associated with incident OAG. We investigated this in a prospective population-based cohort, the Rotterdam Study. A total of 3502 participants aged 55 years and older for whom dietary data at baseline and ophthalmic data at baseline and follow-up were
\end{abstract}

W. D. Ramdas · R. C. W. Wolfs · A. Hofman ·

J. R. Vingerling $(\varangle) \cdot$ N. M. Jansonius

Department of Epidemiology, Erasmus Medical Center

Rotterdam, PO Box 2040, 3000 CA Rotterdam, The Netherlands

e-mail: j.vingerling@erasmusmc.nl

R. C. W. Wolfs · J. R. Vingerling

Department of Ophthalmology, Erasmus Medical Center

Rotterdam, PO Box 2040, 3000 CA Rotterdam, The Netherlands

J. C. Kiefte-de Jong

Department of Pediatrics, Erasmus Medical Center Rotterdam,

Rotterdam, The Netherlands

P. T. V. M. de Jong

Department of Ophthalmogenetics, The Netherlands Institute for Neuroscience, RNAAS, Amsterdam, The Netherlands

P. T. V. M. de Jong

Department of Ophthalmology, Academic Medical Center,

Amsterdam, The Netherlands

N. M. Jansonius

Department of Ophthalmology, University Medical Center

Groningen, University of Groningen, Groningen,

The Netherlands available and who did not have OAG at baseline were included. The ophthalmic examinations comprised measurements of the IOP and perimetry; dietary intake of nutrients was assessed by validated questionnaires and adjusted for energy intake. Cox proportional hazard regression analysis was applied to calculate hazard ratios of associations between the baseline intake of nutrients and incident OAG, adjusted for age, gender, IOP, IOP-lowering treatment, and body mass index. During an average follow-up of 9.7 years, 91 participants $(2.6 \%)$ developed OAG. The hazard ratio for retinol equivalents (highest versus lowest tertile) was 0.45 (95\% confidence interval $0.23-0.90)$, for vitamin B1 0.50 (0.25-0.98), and for magnesium 2.25 (1.16-4.38). The effects were stronger after the exclusion of participants taking supplements. Hence, a low intake of retinol equivalents and vitamin B1 (in line with hypothesis) and a high intake of magnesium (less unambiguous to interpret) appear to be associated with an increased risk of OAG.

Keywords Glaucoma - Nutrition - Magnesium ·

Vitamin A · Vitamin B1 · Population-based · Dietary intake

\section{Introduction}

One of the most important sight-threatening eye disorders in ophthalmology is open-angle glaucoma (OAG). This progressive neurodegenerative disease leads to glaucomatous optic neuropathy and eventually, through glaucomatous visual field loss, to loss of sight. Together with agerelated macular degeneration it is the most common cause of irreversible blindness.

An increased intraocular pressure (IOP) is the main risk factor for OAG, but IOP-independent mechanisms play a role as well: some people develop OAG without an 
elevated IOP and in others the deterioration continues despite an apparently sufficient reduction of the IOP. Neurodegeneration and an impaired ocular blood flow are examples of mechanisms supposed to contribute to the IOPindependent deterioration in OAG; oxidative stress is presumed to be part of the neurodegenerative process [1-4]. Apart from its neurodegenerative effect on the optic nerve, oxidative stress has also been suggested to damage the trabecular meshwork, resulting in an increase in the IOP [2]. For these reasons, the effects of nutrients with anti-oxidant activity are of great interest [5], especially because the intake of nutrients is modifiable. It has been shown that differences in intake of anti-oxidants may influence the course of an eye disease (e.g., age-related macular degeneration), even in the western world without apparent malnutrition [6, 7]. Common nutrients with anti-oxidant activity are carotenoids (present in most fruits and vegetables), retinol equivalents, vitamins $\mathrm{B}, \mathrm{C}$ and $\mathrm{E}$, and polyphenolic flavonoids (present in tea, especially green tea, and coffee).

The second presumed mechanism for an IOP-independent deterioration in OAG was an impaired blood flow. Nutrients of interest here are the omega- 3 and omega- 6 fatty acids, and magnesium. The fatty acids are well known in the cardiovascular literature because of their effect on blood flow regulation by serving as direct precursors of prostaglandins. It has been suggested that they may be of therapeutic value in OAG [8, 9]. Previous studies suggested that magnesium may play a role in the pathogenesis of OAG by affecting the peripheral circulation [10]. Thus far, the possible role of nutrients in OAG was addressed only in the Nurses' Health Study (see "Discussion") [11-13].

The aim of the present study was to explore the influence of nutrients that either have anti-oxidant activity or influence the (ocular) blood flow on the development of OAG. For this purpose, we studied the associations between the intakes of these nutrients and incident OAG in a prospective population-based setting. As there may be effects both directly on the optic nerve and through the IOP, we also studied the associations between these intakes and the IOP.

\section{Methods}

\section{Participants}

The present study was performed within the Rotterdam Study, a prospective population-based cohort study comprising 7,983 residents aged 55 years and older living in Ommoord, a district of Rotterdam, the Netherlands [14]. The baseline examination of the ophthalmic part of the Rotterdam Study included 6,806 participants and took place between 1991 and 1993; follow-up examinations for OAG were performed from 1997 to 1999 and from 2002 to 2006. Participants were included in this study if they (1) participated both at baseline and at least at one follow-up examination, (2) had complete data on OAG and dietary intake, and (3) were not classified as having OAG at baseline. All measurements were conducted after the Medical Ethics Committee of the Erasmus University had approved the study protocol and all participants had given a written informed consent in accordance with the Declaration of Helsinki.

\section{Ophthalmic examination}

The examinations at baseline and follow-up included autorefraction (Topcon RM-A2000; Tokyo Optical Co., Tokyo, Japan), keratometry (Topcon OM-4 Ophthalmometer; Tokyo Optical Co., Tokyo, Japan), measurement of the best corrected visual acuity with ETDRS optotypes, measurement of the IOP (see below), fundus photography of the posterior pole (Topcon TRC-50VT, Tokyo Optical Co., Tokyo, Japan), simultaneous stereoscopic fundus photography of the optic nerve head (Topcon ImageNet System, Topcon TRC-SS2, Tokyo Optical Co., Tokyo, Japan), imaging of the optic nerve head with the Heidelberg Retina Tomograph (Heidelberg Engineering, Dossenheim, Germany) and visual field testing (HFA II 740; Zeiss, Oberkochen, Germany; see below).

The IOP was measured at baseline and at every follow-up round with Goldmann applanation tonometry (Haag-Streit AG, Bern, Switzerland) after applying oxybuprocaine $0.4 \%$ eye drops and fluorescein from a paper strip. Three measurements were taken on each eye and the median value of these three measurements was recorded [15]. In the analysis we used the highest IOP of both eyes.

The visual field of each eye was screened using a 52-point supra-threshold test that covered the central visual field with a radius of $24^{\circ}[16,17]$. Visual field loss was defined as non-response in at least three contiguous test points (or four including the blind spot). In participants with reproducible abnormalities on supra-threshold testing, Goldmann perimetry (Haag-Streit AG, Bern, Switzerland; baseline and first follow-up) or a full-threshold HFA 24-2 test (second follow-up) was performed on both eyes. Details about the classification process were described before [16, 18]. Cases had to have an open anterior chamber angle; a history or signs of secondary glaucoma were not allowed.

Incident OAG was defined as no glaucomatous visual field loss in both eyes at baseline and glaucomatous visual field loss in at least one eye at follow-up [18].

Assessment of nutrient intake

All participants were interviewed at baseline for food assessment using an extensive semiquantitative food 
frequency questionnaire at the study center by a trained dietician. The questionnaire was validated and adapted for use in the elderly [19-21]. It contains 170 food items in 13 food groups and questions about dietary habits and supplementation. The dietary intake of nutrients was calculated using The Dutch Food Composition Database (NEVO) from 1993 to 2006. "Energy-adjusted" nutrient intakes were computed as the unstandardized residuals from a (linear) regression model in which total caloric intake served as the independent variable and the absolute nutrient intake as the dependent variable. Because residuals have a mean of zero and thus include negative values, the expected mean nutrient intakes of the study population was added to the residuals as derived from the regression analysis [22]. Next, we divided the energy-adjusted intake into tertiles (low, medium, and high intake). This process was repeated for all nutrients.

Included nutrients were those that have anti-oxidative properties, being carotenoids ( $\alpha$-carotene, $\beta$-carotene, lutein, zeaxanthin, $\beta$-cryptoxanthin and lycopene), vitamins (retinol equivalents, B1, B6, B12, E and C) and flavonoids, and those that influence the blood flow, being omega-3 fatty acids $(\alpha$-linolenic acid [ALA; C18:3 (n-3) cis], eicosapentaenoic acid [EPA; C20:5 (n-3) cis], docosahexaenoic acid [DHA; C22:6 (n-3) cis]), omega-6 fatty acids (linoleic acid [LA; C18:2 (n-6) cis]) and magnesium. Calcium and phosphorus were included because they compete with magnesium absorption.

As there are two sources of dietary vitamin A (active forms and provitamins), we expressed the amounts of vitamin $\mathrm{A}$ in retinol equivalents.

Body mass index was calculated as weight in kilograms divided by height in meters squared. Weight and height were measured at the research center.

\section{Statistical analysis}

Differences in baseline characteristics were analyzed with independent $t$ tests and Chi-square statistics. Nutrients with $p<0.10$ in the univariate comparisons (between participants with and without incident OAG) were included in a multivariate analysis. For the latter, we used a Cox proportional hazard model to calculate hazard ratios (HR) with corresponding 95\% confidence intervals (CI) to analyze whether participants had a lower or higher risk of incident OAG. Follow-up duration was used as the time variable. Follow-up duration was counted from the baseline visit to the last visit with reliable perimetry. Incident OAG cases were censored at the first visit in which glaucomatous visual field loss was detected. The model was adjusted for age, gender, IOP, IOP-lowering treatment and body mass index, all measured at baseline. Adjustment for IOP was done to analyse whether the effects of the nutrients were independent of IOP. For each nutrient, the lowest tertile (i.e., the participants with the lowest intake) served as the reference group. Tertiles were analyzed as nominal categories, that is, we did not assume beforehand monotonic relationships between nutrient intakes and outcome measure. To evaluate these relationships, linearity was tested by calculating the $p$-trend for the nutrients that showed a significant association with OAG in the final model. We also explored whether there was interaction between age or gender and each of the nutrients from the final model. As a secondary analysis, we repeated the above-mentioned analysis after exclusion of participants who reported to have used any supplements (vitamins or other health pills) at baseline.

To assess the associations between nutrients and IOP, we performed for each nutrient a linear regression analysis (IOP at follow up versus intake). These analyses were adjusted for IOP-lowering treatment at follow-up. Nutrients were analyzed as nominal categories (see above). Nutrients with $p<0.10$ were included in a multiple linear regression analysis with IOP at follow-up as the dependent variable. This model was adjusted for age, gender, body mass index, and IOP-lowering treatment during follow-up.

We used complete case analysis and considered a $p$ value of 0.05 or less statistically significant. All statistical analyses were performed using SPSS version 15.0.0 for Windows (SPSS inc., Chicago, IL, USA; 2006) and R statistical package version 2.11.1 for Mac (http://www.r-project.org).

\section{Results}

A total of 6,806 participants attended the baseline examinations of the ophthalmic part of the Rotterdam Study. From these participants, 6,630 did not have OAG at baseline and 3,939 of 6,630 (59.4\%) completed at least one follow-up round (1,279 died before the first follow-up round, 1473 were unable to participate in the first follow-up round and 143 had unreliable data with regard to OAG; of the participants without (reliable) data at the first follow-up round, 204 successfully completed the second follow-up round). Of these 3,939 participants, $437 \mathrm{did}$ not have reliable data of the food frequency questionnaire or supplement use. This resulted in 3,502 eligible participants for the current study.

During a mean follow-up of 9.7 years (range 5.3-13.9 years), 91 (2.6\%) developed OAG. Table 1 summarizes the general characteristics of the study population at baseline according to incident OAG status. Participants who developed OAG were significantly older, more often men, and had a lower body mass index than those without incident OAG. Their use of supplements did not differ from that of participants without incident OAG $(p=0.86)$. 
Table 1 Baseline characteristics and univariate analyses of the study population with and without incident open-angle glaucoma presented as mean \pm standard deviation (range) unless stated otherwise

\begin{tabular}{lllc}
\hline & $\begin{array}{l}\text { Incident } \\
\text { open-angle } \\
\text { glaucoma } \\
(\mathrm{N}=91)\end{array}$ & $\begin{array}{l}\text { No open- } \\
\text { angle } \\
\text { glaucoma } \\
(\mathrm{N}=3411)\end{array}$ & $p$ value \\
\hline Age (year) & $67.6 \pm 7.0$ & $65.1 \pm 6.6$ & $<0.001$ \\
Gender (N[\%] female) & $47(51.6)$ & $2031(59.5)$ & 0.13 \\
IOP (mmHg) & $17.5 \pm 4.8$ & $15.0 \pm 3.1$ & $<0.001$ \\
IOP-lowering & $14(15.4)$ & $73(2.1)$ & $<0.001$ \\
treatment (N[\%]) & & & \\
Body mass index (kg/m $)$ & $25.5 \pm 2.9$ & $26.3 \pm 3.5$ & 0.03 \\
Supplement users $(\mathrm{N}[\%])$ & $33(36.3)$ & $1269(37.2)$ & 0.86 \\
Diabetes mellitus $(\mathrm{N}[\%])$ & $6(6.6)$ & $126(3.7)$ & 0.16 \\
\hline
\end{tabular}

$I O P$ intraocular pressure

Table 2 shows the descriptive data of the mean daily dietary intake of nutrients for all participants adjusted for total energy intake, with corresponding univariate comparisons between participants with and without incident OAG. At the $p<0.10$ level, participants with incident OAG had a lower intake of $\beta$-carotene, retinol equivalents, vitamin $\mathrm{B} 1$ and vitamin $\mathrm{B} 12$, and a higher intake of magnesium and vitamin $\mathrm{E}$ compared to participants without incident OAG. No other differences in nutrition were found between participants with and without incident OAG. Table 3 shows the results of the multivariate analysis, both for all participants and after exclusion of participants using supplements. High intakes of retinol equivalents and vitamin B1 were associated with a decreased risk of OAG, whereas a high intake of magnesium was associated with an increased risk. For these nutrients the crude hazard ratios (that is, only adjusted for age) were statistically significant as well $(p=0.019, p=0.047$, and $p=0.014$ for high intake of retinol equivalents, vitamin B1 and magnesium, respectively). The $p$-trend for retinol equivalents was 0.018 , for vitamin B1 0.042, and for magnesium 0.014 . We found no significant interactions between age or gender and the nutrients. The effects were stronger if we excluded participants using supplements.

As mentioned in the Introduction, factors may affect the optic nerve head in OAG directly or through the IOP. In the latter case, IOP is in the causal pathway. Although the hypotheses suggest IOP-independent mechanisms for the effects of nutrient intake on OAG, we repeated our analyses without adjustment for IOP and also studied the role of IOP separately. The results of our primary analysis (Table 3) did not change after removing IOP from the model, i.e., the effects appeared to be IOP independent. In the multiple linear regression analysis, there were significant associations for a medium intake of ß-cryptoxanthin (beta: $-0.35 \mathrm{mmHg} ; p=0.049$ ) and a medium intake of vitamin $\mathrm{B} 12$ (beta: $-0.35 \mathrm{mmHg} ; p=0.039$ ) with IOP. A high intake of these two nutrients, however, was not significantly associated with IOP, precluding the presence of a clear dose-response relationship.

\section{Discussion}

Retinol equivalents and vitamin B1 seem to have a protective effect on OAG, whereas magnesium intake appears to be associated with an increased risk. Since the analyses were adjusted for IOP, these effects should be considered IOP-independent. This is in agreement with the fact that we did not find a significant effect of these nutrients on IOP. None of the other nutrients had an unequivocal effect on IOP as well. The effects of retinol equivalents, vitamin B1 and magnesium on OAG became stronger when excluding participants taking supplements.

Little is known about the possible associations between nutrition and OAG. The Nurses' Health Study and the Health Professionals Follow-up Study, two large prospective cohorts comprising over 100,000 participants, studied the influence of nutrients with anti-oxidative properties on OAG. They could not find a significant association [11]. Our results on antioxidants (with the exception of vitamin A) were in line with their results (no significant effect on OAG). A possible explanation for the non-significant finding of vitamin $\mathrm{A}$ in their study might be that their OAG cases were based on selfreport. After all, glaucoma is an insidious eye disease and about half of the OAG patients are undetected at a certain moment $[17,23]$. This may cause a selection bias in studies based on self-report (or studies performed in a clinical environment). Our population-based approach in which the OAG cases were detected by systematic screening only should be robust with regard to such a selection bias. A striking difference between the Nurses' Health and Health Professional Follow-up Study and our study is a difference in baseline IOP: $75.5 \%$ of the participants in the Nurses' Health and Health Professional Follow-up Study had an IOP $>22 \mathrm{mmHg}$ compared to only $15.4 \%$ in our study. Furthermore, participants of the Nurses' Health Study and the Health Professional Follow-up Study were younger (30-75 years; mean age $\sim 49$ years) compared to those from the current study ( $>55$ years; mean age 65.2 years). Dietary intake, metabolism, and absorption of nutrients are different in the elderly. The effect of vitamin A on the development of OAG may be different in young people developing high-tension glaucoma compared to elderly people developing normal-tension glaucoma. Unfortunately, power limitations inhibited the conduct of interaction analyses between vitamin A, baseline IOP and age. Of interest is that vitamin $\mathrm{A}$ and retinoic acid (a metabolite of vitamin A) were shown to have a therapeutic effect in 
Table 2 Mean dietary intake of the assessed nutrients by tertile (low, medium and high intake), adjusted for total energy intake for each tertile, with corresponding univariate comparisons between participants with and without incident open-angle glaucoma

\begin{tabular}{|c|c|c|c|c|c|c|c|}
\hline \multirow[t]{2}{*}{ Nutrient } & \multicolumn{2}{|l|}{ Low intake } & \multicolumn{2}{|l|}{ Medium intake } & \multicolumn{2}{|l|}{ High intake } & \multirow[t]{2}{*}{$p$ value* } \\
\hline & Mean \pm SD & Range & Mean \pm SD & Range & Mean $\pm \mathrm{SD}$ & Range & \\
\hline \multicolumn{8}{|c|}{ With anti-oxidative properties } \\
\hline $\begin{array}{l}\alpha \text {-carotene } \\
(\mu \mathrm{g} / \text { day })\end{array}$ & $590.72 \pm 205.44$ & $(<852.18)$ & $1059.18 \pm 119.34$ & $(852.40-1278.48)$ & $1851.95 \pm 996.30$ & $(>1278.76)$ & 0.438 \\
\hline $\begin{array}{l}\text { B-carotene } \\
(\mu \mathrm{g} / \text { day })\end{array}$ & $2431.61 \pm 613.88$ & $(<3216.03)$ & $3775.53 \pm 334.72$ & $(3219.18-4399.33)$ & $5879.44 \pm 2609.44$ & $(>4399.61)$ & 0.075 \\
\hline Lutein $(\mu \mathrm{g} /$ day $)$ & $1417.24 \pm 318.64$ & $(<1842.51)$ & $2164.79 \pm 188.46$ & $(1842.72-2504.99)$ & $3235.32 \pm 1156.42$ & $(>2506.38)$ & 0.238 \\
\hline $\begin{array}{l}\text { Zeaxanthin } \\
(\mu \mathrm{g} / \text { day })\end{array}$ & $72.54 \pm 17.16$ & $(<96.48)$ & $117.06 \pm 11.85$ & $(96.49-137.88)$ & $175.99 \pm 46.14$ & $(>137.89)$ & 0.865 \\
\hline $\begin{array}{l}\text { B-cryptoxanthin } \\
\text { ( } \mu \mathrm{g} / \text { day) }\end{array}$ & $74.77 \pm 53.60$ & $(<173.59)$ & $265.80 \pm 61.07$ & $(174.27-371.22)$ & $530.05 \pm 191.52$ & $(>371.31)$ & 0.809 \\
\hline $\begin{array}{l}\text { Retinol } \\
\text { equivalents } \\
\text { (mg/day) }\end{array}$ & $0.57 \pm 0.10$ & $(<0.68)$ & $0.76 \pm 0.04$ & $(0.68-0.84)$ & $1.11 \pm 0.46$ & $(>0.84)$ & 0.003 \\
\hline $\begin{array}{l}\text { Vitamin B1 } \\
\text { (mg/day) }\end{array}$ & $0.87 \pm 0.11$ & $(<1.01)$ & $1.11 \pm 0.06$ & $(1.01-1.22)$ & $1.39 \pm 0.15$ & $(>1.22)$ & 0.017 \\
\hline $\begin{array}{l}\text { Vitamin B6 } \\
\text { (mg/day) }\end{array}$ & $1.31 \pm 0.14$ & $(<1.47)$ & $1.59 \pm 0.07$ & $(1.47-1.70)$ & $1.92 \pm 0.21$ & $(>1.70)$ & 0.988 \\
\hline $\begin{array}{l}\text { Vitamin B12 } \\
\text { (mg/day) }\end{array}$ & $2.78 \pm 0.75$ & $(<3.69)$ & $4.33 \pm 0.39$ & $(3.70-5.07)$ & $8.48 \pm 6.92$ & $(>5.08)$ & 0.066 \\
\hline $\begin{array}{l}\text { Vitamin C } \\
\text { (mg/day) }\end{array}$ & $72.07 \pm 17.17$ & $(<96.49)$ & $114.99 \pm 10.87$ & $(96.50-134.74)$ & $177.97 \pm 45.30$ & $(>134.79)$ & 0.956 \\
\hline $\begin{array}{l}\text { Vitamin E } \\
\text { (mg/day) }\end{array}$ & $8.83 \pm 1.99$ & $(<11.38)$ & $13.29 \pm 1.13$ & $(11.38-15.33)$ & $19.42 \pm 4.04$ & $(>15.35)$ & 0.086 \\
\hline Flavonoids & $16.52 \pm 4.77$ & $(<23.09)$ & $27.94 \pm 2.89$ & $(23.10-33.23)$ & $42.18 \pm 8.70$ & $(>33.23)$ & 0.923 \\
\hline \multicolumn{8}{|l|}{ Affecting blood flow } \\
\hline $\begin{array}{l}\text { ALA (C18:3 } \\
\text { (n-3) cis) (g/day) }\end{array}$ & $0.62 \pm 0.14$ & $(<0.81)$ & $0.95 \pm 0.09$ & $(0.81-1.12)$ & $1.56 \pm 0.44$ & $(>1.12)$ & 0.470 \\
\hline $\begin{array}{l}\text { EPA (C20:5 (n-3) } \\
\text { cis) (g/day) }\end{array}$ & $0.00 \pm 0.01$ & $(<0.01)$ & $0.03 \pm 0.01$ & $(0.01-0.05)$ & $0.11 \pm 0.09$ & $(>0.05)$ & 0.729 \\
\hline $\begin{array}{l}\text { DHA (C22:6 } \\
(\mathrm{n}-3) \text { cis })(\mathrm{g} / \text { day })\end{array}$ & $0.02 \pm 0.01$ & $(<0.04)$ & $0.07 \pm 0.02$ & $(0.04-0.10)$ & $0.21 \pm 0.14$ & $(>0.11)$ & 0.704 \\
\hline $\begin{array}{l}\text { LA (C18:2 (n-6) } \\
\text { cis) (g/day) }\end{array}$ & $6.37 \pm 2.47$ & $(<9.47)$ & $12.04 \pm 1.56$ & $(9.48-14.94)$ & $19.87 \pm 4.54$ & $(>14.94)$ & 0.410 \\
\hline Calcium (mg/day) & $773.27 \pm 149.99$ & $(<964.91)$ & $1095.41 \pm 76.58$ & (965.19-1238.44) & $1527.75 \pm 285.00$ & $(>1238.61)$ & 0.358 \\
\hline $\begin{array}{l}\text { Phosphorus } \\
\text { (mg/day) }\end{array}$ & $1117.50 \pm 144.93$ & $(<1319.64)$ & $1515.03 \pm 130.32$ & (1320.59-1786.33) & $2498.47 \pm 777.77$ & $(>1787.00)$ & 0.865 \\
\hline $\begin{array}{l}\text { Magnesium } \\
(\mathrm{mg} / \text { day) }\end{array}$ & $252.94 \pm 28.63$ & $(<287.87)$ & $309.41 \pm 12.38$ & $(287.88-331.51)$ & $369.48 \pm 34.67$ & $(>331.52)$ & 0.001 \\
\hline
\end{tabular}

* $p$ Values of the univariate analyses between participants with and without incident open-angle glaucoma

$s d$ standard deviation, $A L A \alpha$-linolenic acid, EPA eicosapentaenoic acid, DHA docosahexaenoic acid, $L A$ linoleic acid

Alzheimer's disease, like OAG a neurodegenerative disorder $[24,25]$. This effect may be due to the anti-amyloidogenic properties of retinoic acid (and vitamin A) [26]. Several studies implicated amyloid-beta deposition in Alzheimer's disease. It has been shown that amyloid-beta is involved in retinal ganglion cell apoptosis in OAG [27]. In animals, retinoic acid plays a role in optic nerve regeneration after injury [28]. Food sources rich in retinol equivalents are dairy products (milk, cheese, butter) and liver.
Patients with OAG are reported to have a lower thiamine (vitamin B1) level than controls [29]. This supports the current finding of a protective effect of vitamin B1. We showed the protective effect of vitamin B1 on OAG to be independent of IOP. This is in agreement with the association between vitamin B1 deficiency and degeneration of ganglion cells of the brain and spinal cord in animal experiments [30], and between vitamin B1 deficiency and a reduced thickness of the retinal ganglion cell layer in rats 
Table 3 Multivariate analysis for nutrition and open-angle glaucoma, for all participants and after exclusion of participants taking supplements

\begin{tabular}{|c|c|c|}
\hline & $\begin{array}{l}\text { Hazard ratio } \\
\text { (95\% CI; } p \text { value) }\end{array}$ & $\begin{array}{l}\text { Hazard ratio } \\
(95 \% \mathrm{CI} ; p \text { value })^{*}\end{array}$ \\
\hline Age (year) & $\begin{array}{l}1.07(1.04-1.11 \\
\quad<0.001)\end{array}$ & $\begin{array}{l}1.09(1.05-1.14 \\
<0.001)\end{array}$ \\
\hline Gender & $\begin{array}{l}0.74(0.48-1.15 \\
0.178)\end{array}$ & $\begin{array}{l}0.72(0.41-1.25 \\
0.243)\end{array}$ \\
\hline IOP (mmHg) & $\begin{array}{l}1.16(1.10-1.22 \\
\quad<0.001)\end{array}$ & $\begin{array}{l}1.17(1.10-1.24 \\
\quad<0.001)\end{array}$ \\
\hline $\begin{array}{l}\text { IOP-lowering } \\
\text { treatment }\end{array}$ & $\begin{array}{l}3.87(1.95-7.69 \\
\quad<0.001)\end{array}$ & $\begin{array}{l}6.21(2.68-14.41 \\
\quad<0.001)\end{array}$ \\
\hline $\begin{array}{l}\text { Body mass index } \\
\left(\mathrm{kg} / \mathrm{m}^{2}\right)\end{array}$ & $\begin{array}{l}0.93(0.87-0.99 \\
0.026)\end{array}$ & $\begin{array}{l}0.96(0.89-1.04 \\
0.372)\end{array}$ \\
\hline \multicolumn{3}{|l|}{ B-carotene } \\
\hline $1 \mathrm{st}$ & 1.00 (reference) & 1.00 (reference) \\
\hline 2 nd & $\begin{array}{l}1.62(0.97-2.71 ; \\
0.063)\end{array}$ & $\begin{array}{l}0.99(0.52-1.86 \\
0.966)\end{array}$ \\
\hline $3 r d$ & $\begin{array}{l}1.08(0.59-2.00 ; \\
0.795)\end{array}$ & $\begin{array}{l}0.97(0.47-2.00 \\
0.930)\end{array}$ \\
\hline \multicolumn{3}{|l|}{ Retinol equivalents } \\
\hline $1 \mathrm{st}$ & 1.00 (reference) & 1.00 (reference) \\
\hline 2nd & $\begin{array}{l}1.16(0.72-1.87 ; \\
0.543)\end{array}$ & $\begin{array}{l}1.04(0.57-1.89 ; \\
0.901)\end{array}$ \\
\hline $3 r d$ & $\begin{array}{l}0.45(0.23-0.90 \\
0.023)\end{array}$ & $\begin{array}{l}0.33(0.14-0.80 \\
0.014)\end{array}$ \\
\hline \multicolumn{3}{|l|}{ Vitamin B1 } \\
\hline $1 \mathrm{st}$ & 1.00 (reference) & 1.00 (reference) \\
\hline 2 nd & $\begin{array}{l}0.40(0.21-0.77 ; \\
0.006)\end{array}$ & $\begin{array}{l}0.28(0.11-0.68 \\
0.005)\end{array}$ \\
\hline $3 r d$ & $\begin{array}{l}0.50(0.25-0.98 \\
0.044)\end{array}$ & $\begin{array}{l}0.39(0.17-0.90 \\
0.027)\end{array}$ \\
\hline \multicolumn{3}{|l|}{ Vitamin B12 } \\
\hline $1 \mathrm{st}$ & 1.00 (reference) & 1.00 (reference) \\
\hline 2 nd & $\begin{array}{l}1.60(0.97-2.64 ; \\
0.066)\end{array}$ & $\begin{array}{l}1.09(0.55-2.16 \\
0.800)\end{array}$ \\
\hline $3 r d$ & $\begin{array}{l}0.95(0.51-1.78 \\
0.882)\end{array}$ & $\begin{array}{l}1.37(0.65-2.89 ; \\
0.415)\end{array}$ \\
\hline \multicolumn{3}{|l|}{ Vitamin E } \\
\hline $1 \mathrm{st}$ & 1.00 (reference) & 1.00 (reference) \\
\hline 2 nd & $\begin{array}{l}0.69(0.39-1.22 \\
0.199)\end{array}$ & $\begin{array}{l}0.87(0.44-1.74 \\
0.696)\end{array}$ \\
\hline $3 \mathrm{rd}$ & $\begin{array}{l}1.34(0.81-2.22 \\
0.250)\end{array}$ & $\begin{array}{l}1.27(0.66-2.48 ; \\
0.476)\end{array}$ \\
\hline \multicolumn{3}{|l|}{ Magnesium } \\
\hline 1 st & 1.00 (reference) & 1.00 (reference) \\
\hline 2 nd & $\begin{array}{l}0.54(0.27-1.07 \\
0.076)\end{array}$ & $\begin{array}{l}0.53(0.21-1.35 \\
0.185)\end{array}$ \\
\hline $3 r d$ & $\begin{array}{l}2.25(1.16-4.38 ; \\
0.016)\end{array}$ & $\begin{array}{l}3.19(1.42-7.20 \\
0.005)\end{array}$ \\
\hline
\end{tabular}

* Participants using supplements were excluded $(\mathrm{N}=1302$, of which 33 with open-angle glaucoma, leaving 58 open-angle glaucoma cases)

$C I$ confidence interval, IOP intraocular pressure
[31]. Furthermore, a link between vitamin B1 deficiency and other optic neuropathies is well established [32]. Obviously, most participants with a low intake of vitamin B1 in the current study may not have had a manifest vitamin B1 deficiency. Alcohol consumption could be a confounder here, but alcohol consumption was not associated with either IOP or OAG [33]. Recently, a synthetic derivative of vitamin $\mathrm{B} 1$, sulbutiamine, has been shown to have a neuroprotective effect on retinal ganglion cells, probably due to its anti-apoptotic properties [34]. Food sources rich in vitamin B1 are grain products (bread, rice) and potatoes.

Regarding nutrients affecting blood flow, the Nurses' Health Study and the Health Professionals Follow-up Study showed an increased risk of OAG in participants with a high ratio of omega- 3 to omega- 6 polyunsaturated fat (relative risk [95\% CI]: 1.49 [1.11-2.01]) [12]. However, the latter association was only present in participants with high-tension OAG (OAG with IOP $>21 \mathrm{mmHg}$; relative risk [95\% CI]: 1.68 [1.18-2.40]) and not in participants with normal-tension OAG (OAG with IOP $\leq 21 \mathrm{mmHg}$; relative risk [95\% CI]: 0.82 [0.20-3.47]). The ratio of omega-3 to omega-6, adjusted for total energy intake, was in our study higher in participants with OAG (mean 0.19) compared to participants without OAG (0.12), but this difference did not reach statistical significance $(p=0.22)$. This lack of significance might be explained by power limitations or by the fact that the majority $(79 \%)$ of our incident OAG cases had an IOP $\leq 21 \mathrm{mmHg}$ and were untreated at baseline. The corresponding small number of cases with an IOP $>21 \mathrm{mmHg}$ or on IOP-lowering treatment at baseline hampers a secondary subgroup analysis.

A review of natural therapies (that is, by means of changing nutrition habits) for ocular disorders highlighted the role of magnesium supplementation in OAG therapy [30]. Magnesium administration improves the peripheral circulation [35] and has been reported to have a beneficial effect on the visual field in patients with OAG with coldinduced vasospasm [10]. However, there are some concerns regarding the latter study. They included only ten glaucoma patients (of which six with OAG) and observed an improvement after a very short follow-up. This suggests a short-term effect on the sensitivity of the visual system rather than a real effect on glaucoma progression. Moreover, the observed change was small and did not reach statistical significance $(p=0.09)$ [36]. As mentioned in the Methods section, magnesium absorption competes with that of phosphorus and calcium; however, we found no significant interaction between these nutrients (data not shown). Furthermore, magnesium is present in many fruits, vegetables, beans and dairy products, and thus, the association of magnesium with OAG might be explained by other nutrients present in magnesium-rich products. 
Interestingly, the rationale of magnesium substitution is that magnesium has similar effects as calcium channel blockers [10, 37]. A double-blind controlled trial with oral magnesium aspartate $\mathrm{HCl}$ supplements, presented an inverse association with systemic blood pressure [38]. The role of calcium channel blockers in $\mathrm{OAG}$, however, is all but clear. Several clinical studies suggested a small protective effect [39-41], but two large epidemiological studies including our study reported a harmful effect. These contradictory findings may be attributed to patient selection [42, 43]. Adjusting for the use of calcium channel blockers at baseline did not alter the harmful effect of magnesium in our study (data not shown). As the influence of calcium channel blockers on OAG is unclear, it is difficult to interpret our findings on magnesium.

The strengths of the present study are its population-based setting and the long follow-up. The study population presumably consumed a healthy diet as the median nutrient intake of the study population was at or above the recommended daily allowance [6]. A possible limitation of our study is that only one food frequency questionnaire was used at baseline. Although this could initiate misclassification (dietary changes may result, amongst others, as part of treatment for chronic illnesses like hypertension, diabetes mellitus and age-related macular degeneration), such misclassification would unlikely result in false-positive findings (none of the illnesses that have dietary measures as part of its treatment are clearly associated with $\mathrm{OAG}$ ). Another possible limitation is the limited number of participants who developed OAG during follow-up. Almost half of the cohort deceased or did not participate at follow-up. Although a selective non-response is possible, we found no significant differences in dietary intake of nutrients or intake of supplements between participants and non-participants. The only relevant differences in baseline characteristics were age and gender: non-participants were significantly older and more often women [18]. As high age is associated with an increased risk of OAG and a decreased dietary intake, nonparticipation might have resulted in an underestimation of our findings. No differences in IOP or body mass index were observed between participants and non-participants. As we tested a large number of nutrients, this might have resulted in false-positive findings. To cope at least partially with this, we only included nutrients that were earlier addressed in the literature or for which a clear pathophysiological rationale could be found (see "Introduction" section). If we would apply the very strict Bonferroni correction for multiple comparisons to the univariate analyses as presented in Table 1, a $p$ value of $0.003(0.05 / 19)$ would have been considered as statistically significant in the univariate analysis. According to Table 1 magnesium and the retinol equivalents are still significant at this $p$ value.

The percentage of participants taking supplements in our study may seem high (36.2-37.2\%; Table 1), however, it was very similar to other studies conducted in the early nineteens (the baseline of this study). For example, the National Health and Nutrition Examination Survey reported that in the age range of 60-69 years, 39.2\% of men and $51.6 \%$ of women used supplements in the United States [44]. A study from Sweden reported supplement use in $22.2 \%$ in men and 33.3\% in women [45]. Finally, we did not adjust for variables like diabetes mellitus, blood pressure and cholesterol level, as was done in the Nurses' Health Study and the Health Professionals Follow-up Study [11]. However, in the present study none of these variables showed significant univariate differences at baseline $(p=0.158, p=0.976$ and $p=0.682$, respectively; Table 1$)$, and thus they would have been excluded from the final model-if they would have been included initially. The same holds for smoking; previously, we reported no association between smoking and OAG [33]. Although diabetes mellitus was reported not to be associated with OAG in the Rotterdam Study [46], some studies suggest the opposite. Furthermore, magnesium has been associated with diabetes mellitus. For these reasons, we performed an additional analysis by adding diabetes mellitus to the model. This did not change the findings (data not shown).

In conclusion, the current findings suggest that people with a high intake of retinol equivalents or vitamin $\mathrm{B} 1$ have an about twofold lower risk of OAG compared to those with a low intake of these nutrients, and people with a high intake of magnesium have an about threefold increase in risk of OAG compared to those with a low intake. These findings might be helpful in the unraveling of the largely unknown pathophysiology of OAG.

Acknowledgments The financial support, in this study is given by Stichting Lijf en Leven, Krimpen aan de Lek; MD Fonds, Utrecht; Rotterdamse Vereniging Blindenbelangen, Rotterdam; Stichting Oogfonds Nederland, Utrecht; Blindenpenning, Amsterdam; Blindenhulp, The Hague; Algemene Nederlandse Vereniging ter Voorkoming van Blindheid (ANVVB), Doorn; Landelijke Stichting voor Blinden en Slechtzienden, Utrecht; Swart van Essen, Rotterdam; Stichting Winckel-Sweep, Utrecht; Henkes Stichting, Rotterdam; Laméris Ootech BV, Nieuwegein; Medical Workshop, de Meern; Topcon Europe BV, Capelle aan de IJssel, all in the Netherlands, and Heidelberg Engineering, Dossenheim, Germany.

\section{Conflict of interest None.}

Open Access This article is distributed under the terms of the Creative Commons Attribution License which permits any use, distribution, and reproduction in any medium, provided the original author(s) and the source are credited.

\section{References}

1. Cheung W, Guo L, Cordeiro MF. Neuroprotection in glaucoma: drug-based approaches. Optom Vis Sci. 2008;85(6):406-16. 
2. Izzotti A, Bagnis A, Sacca SC. The role of oxidative stress in glaucoma. Mutat Res. 2006;612(2):105-14.

3. Kumar DM, Agarwal N. Oxidative stress in glaucoma: a burden of evidence. J Glaucoma. 2007;16(3):334-43.

4. Zanon-Moreno V, Marco-Ventura P, Lleo-Perez A, et al. Oxidative stress in primary open-angle glaucoma. J Glaucoma. 2008; 17(4):263-8.

5. Mozaffarieh M, Grieshaber MC, Orgul S, Flammer J. The potential value of natural antioxidative treatment in glaucoma. Surv Ophthalmol. 2008;53(5):479-505.

6. van Leeuwen R, Boekhoorn S, Vingerling JR, et al. Dietary intake of antioxidants and risk of age-related macular degeneration. JAMA. 2005;294(24):3101-7.

7. Rehak M, Fric E, Wiedemann P. Lutein and antioxidants in the prevention of age-related macular degeneration. Ophthalmologe. 2008;105(1):37-38-40-45. doi:10.1007/s00347-007-1602-1.

8. Mozaffarieh M, Flammer J. A novel perspective on natural therapeutic approaches in glaucoma therapy. Expert Opin Emerg Drugs. 2007;12(2): 195-8.

9. Cellini M, Caramazza N, Mangiafico P, Possati GL, Caramazza R. Fatty acid use in glaucomatous optic neuropathy treatment. Acta Ophthalmol Scand. 1998;227:41-2.

10. Gaspar AZ, Gasser P, Flammer J. The influence of magnesium on visual field and peripheral vasospasm in glaucoma. Ophthalmologica. 1995;209(1):11-3.

11. Kang JH, Pasquale LR, Willett W, et al. Antioxidant intake and primary open-angle glaucoma: a prospective study. Am J Epidemiol. 2003;158(4):337-46.

12. Kang JH, Pasquale LR, Willett WC, et al. Dietary fat consumption and primary open-angle glaucoma. Am J Clin Nutr. 2004; 79(5):755-64.

13. West AL, Oren GA, Moroi SE. Evidence for the use of nutritional supplements and herbal medicines in common eye diseases. Am J Ophthalmol. 2006;141(1):157-66. doi:10.1016/j.ajo.2005.07.033.

14. Hofman A, van Duijn CM, Franco OH, Ikram MA, Janssen HL, Klaver CC, Kuipers EJ, Nijsten TE, Stricker BH, Tiemeier H, Uitterlinden AG, Vernooij MW, Witteman JC. The Rotterdam Study: 2012 objectives and design update. Eur J Epidemiol. 2011: 26(8):657-86.

15. Dielemans I, Vingerling JR, Hofman A, Grobbee DE, de Jong PT. Reliability of intraocular pressure measurement with the Goldmann applanation tonometer in epidemiological studies. Graefes Arch Clin Exp Ophthalmol. 1994;232(3):141-4.

16. Skenduli-Bala E, de Voogd S, Wolfs RC, et al. Causes of incident visual field loss in a general elderly population: the Rotterdam study. Arch Ophthalmol. 2005;123(2):233-8. doi:10.1001/ archopht.123.2.233.

17. Wolfs RC, Borger PH, Ramrattan RS, et al. Changing views on open-angle glaucoma: definitions and prevalences-the Rotterdam Study. Invest Ophthalmol Vis Sci. 2000;41(11):3309-21.

18. Czudowska MA, Ramdas WD, Wolfs RC, et al. Incidence of glaucomatous visual field loss: a ten-year follow-up from the Rotterdam Study. Ophthalmology. 2010;117(9):1705-12.

19. Klipstein-Grobusch K, den Breeijen JH, Goldbohm RA, et al. Dietary assessment in the elderly: validation of a semiquantitative food frequency questionnaire. Eur J Clin Nutr. 1998;52(8): 588-96.

20. Goldbohm RA, van den Brandt PA, Brants HA, et al. Validation of a dietary questionnaire used in a large-scale prospective cohort study on diet and cancer. Eur J Clin Nutr. 1994;48(4):253-65.

21. Goldbohm RA, van 't Veer P, van den Brandt PA, et al. Reproducibility of a food frequency questionnaire and stability of dietary habits determined from five annually repeated measurements. Eur J Clin Nutr. 1995;49(6):420-9.

22. Willett W. Nutritional epidemiology. USA: Oxford University Press; 1990.
23. Hollows FC, Graham PA. Intra-ocular pressure, glaucoma, and glaucoma suspects in a defined population. $\mathrm{Br} \mathrm{J}$ Ophthalmol. 1966;50(10):570-86.

24. Lee HP, Casadesus G, Zhu X, et al. All-trans retinoic acid as a novel therapeutic strategy for Alzheimer's disease. Expert Rev Neurother. 2009;9(11):1615-21. doi:10.1586/ern.09.86.

25. McKinnon SJ. Glaucoma: ocular Alzheimer's disease? Front Biosci. 2003;8:s1140-56.

26. Takasaki J, Ono K, Yoshiike Y, et al. Vitamin A has anti-oligomerization effects on amyloid-beta in vitro. J Alzheimers Dis. 2011;. doi:10.3233/JAD-2011-110455.

27. Guo L, Salt TE, Luong V, et al. Targeting amyloid-beta in glaucoma treatment. Proc Natl Acad Sci USA. 2007;104(33): 13444-9. doi:10.1073/pnas.0703707104.

28. Nagashima M, Sakurai H, Mawatari K, Koriyama Y, Matsukawa $\mathrm{T}$, Kato $\mathrm{S}$. Involvement of retinoic acid signaling in goldfish optic nerve regeneration. Neurochem Int. 2009;54(3-4):229-36. doi: 10.1016/j.neuint.2008.11.007.

29. Asregadoo ER. Blood levels of thiamine and ascorbic acid in chronic open-angle glaucoma. Ann Ophthalmol. 1979;11(7): 1095-100.

30. Head KA. Natural therapies for ocular disorders, part two: cataracts and glaucoma. Altern Med Rev. 2001;6(2):141-66.

31. Ramakrishna T. Vitamins and brain development. Physiol Res. 1999;48(3):175-87.

32. Suzuki S, Kumanomido T, Nagata E, Inoue J, Niikawa O. Optic neuropathy from thiamine deficiency. Intern Med. 1997;36(7): 532.

33. Ramdas WD, Wolfs RC, Hofman A, de Jong PT, Vingerling JR, Jansonius NM. Lifestyle and risk of developing open-angle glaucoma: the Rotterdam Study. Arch Ophthalmol. 2011;129(6): 767-72. doi:10.1001/archophthalmol.2010.373.

34. Kang KD, Majid AS, Kim KA, et al. Sulbutiamine counteracts trophic factor deprivation induced apoptotic cell death in transformed retinal ganglion cells. Neurochem Res. 2010;35(11): 1828-39. doi:10.1007/s11064-010-0249-5.

35. Mozaffarieh M, Flammer J. Is there more to glaucoma treatment than lowering IOP? Surv Ophthalmol. 2007;52(Suppl 2):S174-9. doi:10.1016/j.survophthal.2007.08.013.

36. Winterkorn JM. The influence of magnesium on visual field and peripheral vasospasm in glaucoma. Surv Ophthalmol. 1995; 40(1):83-4.

37. Johnson S. The multifaceted and widespread pathology of magnesium deficiency. Med Hypotheses. 2001;56(2):163-70. doi: 10.1054/mehy.2000.1133.

38. Witteman JC, Grobbee DE, Derkx FH, Bouillon R, de Bruijn AM, Hofman A. Reduction of blood pressure with oral magnesium supplementation in women with mild to moderate hypertension. Am J Clin Nutr. 1994;60(1):129-35.

39. Koseki N, Araie M, Tomidokoro A, et al. A placebo-controlled 3-year study of a calcium blocker on visual field and ocular circulation in glaucoma with low-normal pressure. Ophthalmology. 2008;115(11):2049-57. doi:10.1016/j.ophtha.2008.05.015.

40. Kitazawa Y, Shirai H, Go FJ. The effect of Ca2(+) -antagonist on visual field in low-tension glaucoma. Graefes Arch Clin Exp Ophthalmol. 1989;227(5):408-12.

41. Koseki N, Araie M, Yamagami J, Shirato S, Yamamoto S. Effects of oral brovincamine on visual field damage in patients with normal-tension glaucoma with low-normal intraocular pressure. J Glaucoma. 1999;8(2):117-23.

42. Muskens RP, de Voogd S, Wolfs RC, et al. Systemic antihypertensive medication and incident open-angle glaucoma. Ophthalmology. 2007;114(12):2221-6. doi:10.1016/j.ophtha.2007. 03.047.

43. Langman MJ, Lancashire RJ, Cheng KK, Stewart PM. Systemic hypertension and glaucoma: mechanisms in common and 
co-occurrence. $\mathrm{Br} \quad \mathrm{J}$ Ophthalmol. 2005;89(8):960-3. doi: 10.1136/bjo.2004.053397.

44. Balluz LS, Kieszak SM, Philen RM, Mulinare J. Vitamin and mineral supplement use in the United States. Results from the third National Health and Nutrition Examination Survey. Arch Fam Med. 2000;9(3):258-62.

45. Messerer M, Johansson SE, Wolk A. Sociodemographic and health behaviour factors among dietary supplement and natural remedy users. Eur J Clin Nutr. 2001;55(12):1104-10. doi: 10.1038/sj.ejcn.1601272.

46. de Voogd S, Ikram MK, Wolfs RC, et al. Is diabetes mellitus a risk factor for open-angle glaucoma? the Rotterdam Study. Ophthalmology. 2006;113(10):1827-31. doi:10.1016/j.ophtha.2006.03.063. 